\title{
A Novel Para-Amino Salicylic Acid Magnesium Layered Hydroxide Nanocomposite Anti-Tuberculosis Drug Delivery System with Enhanced in vitro Therapeutic and Anti-Inflammatory Properties
}

\author{
Bullo Saifullah ${ }^{1,2}$ \\ Palanisamy Arulselvan (iD 3,4 \\ Mohamed E El Zowalaty (D) \\ Woan Sean $\operatorname{Tan}^{3}$ \\ Sharida Fakurazi ${ }^{6}$ \\ Thomas J Webster (iD ${ }^{7}$ \\ Rabia Baby iD ' \\ Mohd Zobir Hussein (iD) \\ 'Materials Synthesis and Characterization \\ Laboratory, Institute of Advanced \\ Technology (ITMA), Universiti Putra \\ Malaysia, Serdang, Selangor, Malaysia; \\ ${ }^{2}$ Department of Management Sciences \\ and Technology, The Begum Nusrat \\ Bhutto Women University Sukkur, Sukkur, \\ Sindh, 65I70, Pakistan; ${ }^{3}$ Laboratory for \\ Vaccine and Immunotherapeutics, Institute \\ of Biosciences, University Putra Malaysia, \\ Serdang, Selangor, 43400, Malaysia; \\ ${ }^{4}$ Muthayammal Centre for Advanced \\ Research, Muthayammal College of Arts and \\ Science, Namakkal, Tamil Nadu, 637408, \\ India; ${ }^{5}$ Zoonosis Science Center, \\ Department of Microbiology and \\ Immunology, Uppsala University, Uppsala, \\ Sweden; ${ }^{6}$ Department of Human Anatomy, \\ Faculty of Medicine and Health Science, \\ Universiti Putra Malaysia, Serdang, Selangor, \\ Malaysia; ${ }^{7}$ Department of Chemical \\ Engineering, Northeastern University, \\ Boston, MA, USA
}

Correspondence: Mohd Zobir Hussein Materials Synthesis and Characterization Laboratory, Institute of Advanced Technology, (ITMA), Universiti Putra Malaysia, Serdang, Selangor, Malaysia Tel +60397698092

Email mzobir@upm.edu.my
Introduction: Mycobacterium tuberculosis infections are associated with severe local inflammatory reactions, which may be life-threatening and lead to tuberculosis pathogenesis and associated complications. Inorganic nanolayers have been vastly exploited for biomedical applications (especially in drug delivery) because of their biocompatible and biodegradable nature with the ability to release a drug in a sustained manner. Herein, we report a new nanodelivery system of inorganic nanolayers based on magnesium layered hydroxides $(\mathrm{MgLH})$ and a successfully intercalated anti-tuberculosis drug para-aminosalicylic acid (PAS).

Methods: The designed anti-tuberculosis nanodelivery composite, MgLH-PAS, was prepared by a novel co-precipitation method using $\mathrm{MgNO}_{3}$ as well $\mathrm{MgO}$ as starting materials. Results: The designed nano-formulation, PAS-MgLH, showed good antimycobacterial and antimicrobial activities with significant synergistic anti-inflammatory effects on the suppression of lipopolysaccharide (LPS) stimulated inflammatory mediators in RAW 264.7 macrophages. The designed nano-formulation was also found to be biocompatible with human normal lung cells (MRC-5) and 3T3 fibroblast cells. Furthermore, the in vitro release of PAS from PAS-MgLH was found to be sustained in human body simulated phosphate buffer saline (PBS) solutions of $\mathrm{pH} 7.4$ and $\mathrm{pH} 4.8$.

Discussion: The results of the present study are highly encouraging for further in vivo studies. This new nanodelivery system, $\mathrm{MgLH}$, can be exploited in the delivery of other drugs and in numerous other biomedical applications as well.

Keywords: Mycobacterium tuberculosis, magnesium layered hydroxides, biomaterial, sustained release, anti-tuberculosis, anti-inflammatory

\section{Introduction}

Tuberculosis is a devastating bacterial infectious disease caused by Mycobacterium tuberculosis (MTB) or tubercle bacilli. ${ }^{1}$ It existed for centuries and despite technological advancements, we have still not been able to eradicate it. There are only two new drugs that have been found for tuberculosis treatment in the last five decades. ${ }^{2}$ With the currently best available anti-TB drugs, the treatment lasts from 6 to 24 months, depending on the type of TB disease. ${ }^{3}$ According to the latest global tuberculosis 
report in 2020, there were about 10 million new incidents of TB cases worldwide in the year 2019. There were an estimated 1.2 million (range, 1.1-1.3 million) TB deaths among HIV-negative people in 2019. ${ }^{1}$ Tuberculosis is associated with a severe local inflammatory reaction which may be life-threatening and leads to pathogenesis and associated complications. This results in the activation of the innate immune response components and the main recruiters of immune cells, such as polymorphonuclear and mononuclear phagocytes. It also results in the stimulation of numerous primary pro-inflammatory cytokines, such as tumor necrosis factor-alpha (TNF- $\alpha$ ), interleukin 6 , and interleukin $1 \beta$ by the mycobacterium. ${ }^{4-7}$ These inflammatory reactions cause severe damage to the site of the infection. ${ }^{5-7}$

In the present study, we investigated the anti-inflammatory potential of these nanocomposites on LPS-stimulated RAW 264.7 macrophages. PAS is an effective drug, but because of its side effects such as epigastric distress, nausea, anorexia, vomiting, and abdominal cramps or diarrhea, it is no longer used for drug-susceptible TB but is still being used for the treatment of multi-drug resistant TB (MDR-TB). Biocompatible and biodegradable formulations with antiTB, anti-inflammatory and sustained release properties would be very useful to overcome these problems. ${ }^{8,9}$

A layered double hydroxide $(\mathrm{LDH})$ has a basic structure derived from brucite by replacing some of the divalent cations with trivalent ones (such as $\mathrm{Al}^{+3}, \mathrm{Fe}^{+3}$ and $\mathrm{Cr}^{+3}$, etc.), to create a positive charge in the layers. ${ }^{10-13}$ This positive charge is balanced by counter anions between the layers such as nitrate, carbonates, water molecules and most importantly, pharmaceutical drugs in the neutral form with lone pairs or being negatively charged. ${ }^{14}$ Non-toxic characteristics of the anion make them ideal candidates for biomedical and drug delivery applications. ${ }^{10,15-17}$ In this study, we have developed magnesium-layered hydroxides as a drug delivery system without the addition of any trivalent ions in the inorganic layers. Magnesium was chosen based on its high biocompatibility and nutritional value. We intake green vegetables daily where $\mathrm{Mg}^{2+}$ is the central ion present in chlorophyll in vegetables and plants. It is a vital divalent mineral for humans, which is responsible for many enzymatic reactions, such as energy metabolism, and is a vital component of soft tissue forming cells as well as bones and is the most abundant divalent cation in human cells. ${ }^{18-21}$

Different types of layered double hydroxides (LDHs) (eg, Mg/Al-LDHs, Zn/AL-LDHs and in some studies $\mathrm{Fe}^{3+}$ replacing $\mathrm{Al}^{3+}$ ) including zinc layered hydroxides $(\mathrm{ZLH})$ have been exploited as drug delivery agents. They have been reported to be suitable drug delivery agents because of their tendency to release drugs in a sustained manner and be highly biocompatible as well as biodegradable. ${ }^{16,22-25}$ PAS has been loaded with zinc layered hydroxides (ZLH) and $\mathrm{Zn} / \mathrm{Al}-\mathrm{LDHs}{ }^{26,27}$ Compared to these, MgLH is more suitable as it does not require trivalent ions like LDHs and more importantly, magnesium is more biocompatible than $\mathrm{Zn}^{2+}$, as we consume more magnesium in green vegetables on a regular basis. ${ }^{28}$

Magnesium layered hydroxide $(\mathrm{MgLH})$ is a non-toxic material that has a wide range of applications such as in cosmetic products, serving as a catalyst in flame-retardants and has been used as inorganic absorbents, etc. ${ }^{29-31} \mathrm{MgLH}$ has a layered structure in which the hydroxide ions surround the magnesium ion in an octahedral manner. ${ }^{30}$ Infinite layers are formed by these octahedral units by edge-sharing with hydroxide ions in the planes of the layers. In a three-dimensional view, layers stack on top of one another. ${ }^{30,32,33}$ Biocompatible and biodegradable formulations with anti-TB and anti-inflammatory as well as sustained release properties would be very useful to overcome these problems. ${ }^{34,35}$

Many attempts have been made to form a sustained release formulation that could help reduce such side effects such as using buffered tablets, granules, coated tablets and the salt of acids. ${ }^{36-38}$ A biocompatible and biodegradable nanocomposite formulation with sustainedrelease properties would also be helpful in minimizing side effects as the entire drug is not exposed to the human body simultaneously. Instead, the drug is released in a sustained manner which would decrease side effects and would maintain the bioavailability of drugs over a longer time period.

For all of the above reasons, in this study, we successfully intercalated para-aminosalicylic acid (PAS) into magnesium layered hydroxides (PAS-MgLH) by two different methods. In the first method, we used magnesium oxide as the starting material while in the second method, hydrated magnesium nitrate was used instead.

\section{Materials and Methods Chemicals}

Analytical-grade chemicals were used without any further purification. $\mathrm{MgNO}_{3} \cdot 6 \mathrm{H}_{2} \mathrm{O}$ and $\mathrm{MgO}$ were obtained from Sigma-Aldrich (Saint Louis, MO, USA) and methanol was bought from Ajax Finechem (Sydney, Australia). In all experimental work, deionized water was used. 


\section{Cell Culture}

Fibroblast 3T3-Swiss albino (ATCC ${ }^{\circledR}$ CCL-92 ${ }^{\mathrm{TM}}$ ) cells, mouse macrophages (RAW 264.7 cells) and human lung fibroblast MRC-5 (ATCC ${ }^{\circledR}$ CCL-171 ${ }^{\mathrm{TM}}$ ) cells were supplied by ATCC (Manassas, VA, USA). Dulbecco's modified Eagle medium and RPMI 1640 media containing $10 \%$ fetal bovine serum were utilized in the cell culture work. Penicillin at 100 units $/ \mathrm{mL}$ and streptomycin at 50 $\mu \mathrm{g} / \mathrm{mL}$ were added to the growth media. A humidified atmosphere with $5 \% \mathrm{CO}_{2}$, at a temperature of $37{ }^{\circ} \mathrm{C}$, was maintained for all cell culture work.

\section{Preparation of Nanocomposite-A Using $\mathrm{MgO}$ as the Starting Material}

Magnesium oxide (MgO), $0.2 \mathrm{~g}$, was added into $50 \mathrm{~mL}$ of deionized water and stirred for 15 minutes. To this dispersion solution, $50 \mathrm{~mL}\left(25 \mathrm{~mL}\right.$ DMSO $\left.+25 \mathrm{~mL} \mathrm{H}_{2} \mathrm{O}\right)$ of a $0.4 \mathrm{M}$ solution of PAS was added. The $\mathrm{pH}$ of the solution was raised to basic by the slow addition of a $0.5 \mathrm{M}$ solution of sodium hydroxide and the sample was subjected to an oil bath thermal agitation at $70{ }^{\circ} \mathrm{C}$ for one day. On the next day, the sample was washed several times thoroughly with water and then with acetone. Then, the sample was dried in an oven for 2 days at $70{ }^{\circ} \mathrm{C}$ and ground to a powder and kept in a sample bottle for various characterization methods described below. The sample prepared by this method was labeled as Nanocomposite-A.

\section{Preparation of Nanocomposite-B Using Magnesium Nitrate Hexahydrate as the Starting Material}

Magnesium nitrate hexahydrate $(1 \mathrm{~g})$ was dissolved in $50 \mathrm{~mL}$ of deionized water and stirred for 15 minutes. With this solution, $50 \mathrm{~mL}\left(25 \mathrm{~mL}\right.$ DMSO $\left.+25 \mathrm{~mL} \mathrm{H}_{2} \mathrm{O}\right)$ of a $0.4 \mathrm{M}$ solution of PAS was added. The $\mathrm{pH}$ of the solution was raised to basic by the slow addition of $0.5 \mathrm{M}$ sodium hydroxide and the sample was subjected to oil bath thermal agitation at $70^{\circ}$ $\mathrm{C}$ for one day. On the next day, the sample was washed many times thoroughly with water and then acetone. After that, the sample was dried in an oven for 2 days at $70^{\circ} \mathrm{C}$ and ground to a powder for further characterization. The sample prepared by this method was labeled as nanocomposite-B.

\section{Characterization X-Ray Diffraction}

For the X-ray diffraction studies, a Shimadzu XRD-6000 diffractometer (Tokyo, Japan), was used. $\mathrm{CuK}_{\alpha}$ radiation at
$30 \mathrm{kV}$ and $30 \mathrm{Ma}$ was set to record the PXRD patterns. The PXRD patterns were recorded in the $2 \theta$ range of $2-60^{\circ}$ with a scanning speed of 0.5 degrees per minute. The samples were ground to a powder before recording the PXRD patterns.

\section{FTIR Analysis}

A Perkin-Elmer 100 series-spectrophotometer was used to record the Fourier transform infrared (FTIR) spectra of the materials, over a range of $400-4000 \mathrm{~cm}^{-1}$. Each sample was analyzed by a direct method where the sample was directly put on the FTIR sample analyzer to record the spectrum.

\section{Thermogravimetric Analysis}

A Mettler Toledo instrument (Greifensee, Switzerland), was used for the thermogravimetric and differential thermogravimetric (TGA-DTG) analyses. For the thermal analysis, samples were subjected to heating from $25^{\circ} \mathrm{C}$ to $1000^{\circ} \mathrm{C}$ with an increase at a rate of $10^{\circ} \mathrm{C} /$ minute under a continuous nitrogen purge. Mass loss was observed with an increase in temperature.

\section{Transmission Electron Microscopy (TEM) Analysis}

The surface morphology of the sample was analyzed by a Transmission Electron Microscope (TEM). The sample was dispersed in deionized water and sonicated for 5 minutes and a few drops of the samples were poured on the TEM sample grid. After that, the samples were dried at room temperature overnight before analysis.

\section{Dynamic Light Scattering (DLS) Analysis}

The DLS technique was applied for the determination of particle size distribution in a solution as termed hydrodynamic size. The samples were put in deionized water and sonicated for 5 minutes before DLS analysis.

\section{UV/Vis Spectroscopic Analysis}

For optical properties and controlled-release studies, a Shimadzu UV-1650-PC UV/Vis spectrophotometer was employed. Initially, the pure drug, PAS lambda max, the wavelength of maximum absorption was determined to be $265 \mathrm{~nm}$. This wavelength was selected for the drug release studies.

\section{HPLC Analysis}

The drug loading was quantified by a Sykam HPLC system with an auto-injector Sykam 5300, a Sykam S3250 UV/Vis detector and the Sykam quaternary pump system 5300 made in Germany, with a Zorbax Rx-Sil column of $4.6 \times 150 \mathrm{~mm}$, 
and with a $5 \mu \mathrm{m}$ particle size (Agilent). The standard solutions of PAS ie, 10ppm, 20ppm, 30, pm, 40ppm and 50ppm were prepared from the stock solution of PAS. The empty MgLH (without drug) sample solution was also prepared by dissolving it in a $\mathrm{HCl}$ solution for any matrix effect in the HPLC analysis. The mobile phase consisted of a $17.5 \mathrm{mM}$ potassium phosphate buffer as solvent-A with a $\mathrm{pH}$ of 3.5 adjusted by phosphoric acid and methanol as solvent B. Before HPLC analysis, the column was saturated with the mobile phase for 30 minutes.

\section{Sustained-Release Study}

Human body-simulated, $0.1 \mathrm{M}$ phosphate buffer saline (PBS) solutions of $\mathrm{pH}$ values of 7.4 (blood $\mathrm{pH}$ ) and 4.8 (intracellular lysosomal $\mathrm{pH}$ ) were used to study the sustained release of PAS from the inorganic galleries of the nanocomposite. Approximately $0.4 \mathrm{mg}$ each of the Nanocomposite-A and B were placed in $3.5 \mathrm{~mL}$ of $\mathrm{pH}$ 7.4 and 4.8 PBS solutions, and the absorbance at the wavelength $\lambda_{\text {max }}=265 \mathrm{~nm}$ was selected for the UV/Vis spectrophotometer to study drug release from the nanocomposites. The nanocomposites were placed under constant shaking at $37^{\circ} \mathrm{C}$ and at different times, aliquots were taken and replaced back after taking a reading using a UV/ Vis spectrophotometer.

\section{Antimicrobial Susceptibility Test}

The drug susceptibility testing of the nanocomposites was carried out using the BBL nonradiometric fluorescencebased method of MGIT 960 against Mycobacterium tuberculosis $\left(\mathrm{ATCC}^{\circledR} 25618^{\mathrm{TM}}\right.$ ) and the MICs of the nanocomposites were determined as previously described..$^{39,40}$ The Mycobacteria Growth Indicator Tube (MGIT) with BACTEC MGIT 960 growth supplement for drug susceptibility testing was used in an MGIT 960 instrument (Becton Dickinson Diagnostic Systems, Sparks, MD, USA) as described previously. ${ }^{39-41}$

\section{Microbial Growth-Inhibition Kinetics}

The antimicrobial effect of the as-synthesized Nanocomposites-A and B on the growth kinetics of Staphylococcus aureus (ATCC ${ }^{\circledR} 43300^{\mathrm{TM}}$ ), Pseudomonas aeruginosa $\quad\left(\mathrm{ATCC}^{\circledR} 27853^{\mathrm{TM}}\right), \quad$ Escherichia coli (ATCC $^{\circledR} 25922^{\mathrm{TM}}$ ), and Candida albicans (ATCC $^{\circledR} 20408^{\mathrm{TM}}$ ) (ATCC, Manassas, VA, USA) was determined as previously described. ${ }^{39,42-44}$ The percentage inhibition of each nanocomposite against each microorganism was calculated according to the following equation as previously described:

Inhibition rate $=1-\left[\mathrm{CFU}_{\text {treated }} / \mathrm{OD}_{\text {control }}\right] \times 100$ (1)

The efficiency of the nanocomposites to inhibit the growth of the microorganisms was determined by the differences in the equivalent number of colony-forming units before and after treatment as the percentage of microbes that were inhibited by the nanocomposites; this was calculated from the previous equation. ${ }^{39,42-44}$

\section{Cell Viability Assays}

The cytotoxicity of the nanocomposites on 3T3 fibroblasts, RAW 264.7 cells and normal lung fibroblast cells (MRC5) was evaluated by colorimetric (3-(4,5-dimethylthiazol2-yl)-2,5-diphenyltetrazolium bromide) MTT assays. In this experiment, cells were seeded in the 96 well plates (at a cell density of $1 \times 10^{4} /$ well) at various concentrations and incubated overnight to attach the cells. After $24 \mathrm{hrs}$, the seeded cells were exposed to different concentrations of nanoparticles and incubated for another 24 hours at 5\% $\mathrm{CO}_{2}$ and $37^{\circ} \mathrm{C}$. About $20 \mu \mathrm{L}$ of the MTT working solution ( $5 \mathrm{mg} / \mathrm{mL}$ in phosphate-buffered solution) was added to the entire well and incubated at $37^{\circ} \mathrm{C}$ for $3 \mathrm{hrs}$. Finally, the culture media were removed after centrifugation and formazan crystals were dissolved in $100 \mu \mathrm{L}$ of DMSO. The absorbance values were measured at $570 \mathrm{~nm}$ using a microplate reader and cell viability percentage was calculated according to the previously described method. ${ }^{45,46}$

\section{Determination of Nitric Oxide and Pro- Inflammatory Cytokine Production}

The macrophage RAW 264.7 cells were seeded in 6 well plates and incubated overnight. After the incubation period, the seeded cells were pre-treated with different concentrations of nanoparticles and a positive control drug, dexamethasone, for 2 hrs. Further, inflammation was induced by LPS stimulation $(1 \mu \mathrm{g} / \mathrm{mL})$ in pre-treated cells for an additional $24 \mathrm{hrs}$ and the cell culture supernatant was harvested and stored at $-20{ }^{\circ} \mathrm{C}$ until further use. The nitric oxide concentration in the cell culture media was quantified according to previous methods. ${ }^{47}$ Briefly, the effect of nanoparticles on RAW264.7 cell production was determined based on the Griess reaction and the remaining media was used to quantify the production of pro-inflammatory cytokines (IL-6, IL- $1 \beta$ and TNF$\alpha$ ) with ELISA kits (R\&D Systems, Minneapolis, USA) according to the manufacturer's guidelines. 


\section{Statistical Analysis}

The biological assays were conducted from three different independent investigations and expressed as the mean \pm standard deviation (SD). Data are presented as the mean \pm $\mathrm{SD}$ and $\mathrm{P}<0.05$ and $\mathrm{P}<0.001$ were considered as statistically significant. Significant differences were examined using analysis of variance (ANOVA) with SPSS 20.0 software (SPSS Inc., Chicago, IL, USA).

\section{Results}

\section{X-Ray Diffraction and Spatial Orientation of PAS}

Figure 1 shows the X-ray diffraction patterns for the magnesium layered hydroxides $(\mathrm{MgLH})$, the free drug, para-aminosalicylic acid (PAS), Nanocomposite-A and Nanocomposite-B. The magnesium layered hydroxides $(\mathrm{MgLH})$ showed four characteristic reflection peaks: 001, 100,101 and 102 at a $2 \Theta$ value of about $19^{\circ}, 33^{\circ}, 38^{\circ}$ and $52^{\circ}$, respectively. ${ }^{48,49}$ The XRD patterns of Nanocomposite-A and Nanocomposite-B show that the position of the peaks shifted to a lower $2 \Theta$ value of $7.0^{\circ}$. In Nanocomposite- $\mathrm{A}$ and Nanocomposite- $\mathrm{B}$, the basal spacings (d-spacings) increased from $4.73 \AA$ to $12.08 \AA$, and $11.06 \mathrm{~A}^{\circ}$, respectively. The increased basal spacings in both nanocomposites strongly suggest the successful intercalation of PAS into the interlayer galleries of MgLH.

Furthermore, the complete disappearance of reflection peaks, namely $001,100,101,102$ and the appearance of the reflection peaks at a lower $2 \Theta$ value, with higher basal spacing (d-spacing) value, indicates the pure phase of both of the nanocomposites of PAS-MgLH. The XRD patterns of the Nanocomposite-A show three reflections, with the first, second and third with a basal spacing of $12.08 \AA$, $6.29 \AA$ and $4.24 \AA$, respectively. On the other hand, Nanocomposite-B (Figure 1A) also shows the three reflections with a basal spacing of $11.65 \AA, 6.36 \AA$ and $4.35 \AA$. These reflections suggest that both nanocomposites are highly crystalline. Thus, the XRD results confirmed the successful intercalation of PAS into the interlayer galleries of MgLH and that the resulting composites are highly crystalline and relatively pure.

The spatial orientation of PAS in the interlayer galleries of MgLH was proposed by calculating the average basal spacing of all the PXRD reflections in both Nanocomposite-A and Nanocomposite-B. The average basal spacing of the Nanocomposite-A was found to be approximately $12.47 \AA$ and the Nanocomposite-B was $12.49 \AA$. The three-dimensional molecular size of PAS in the $\mathrm{X}, \mathrm{Y}$ and $\mathrm{Z}$ axes have been reported to be $9.4 \AA, 7.1 \AA$
A

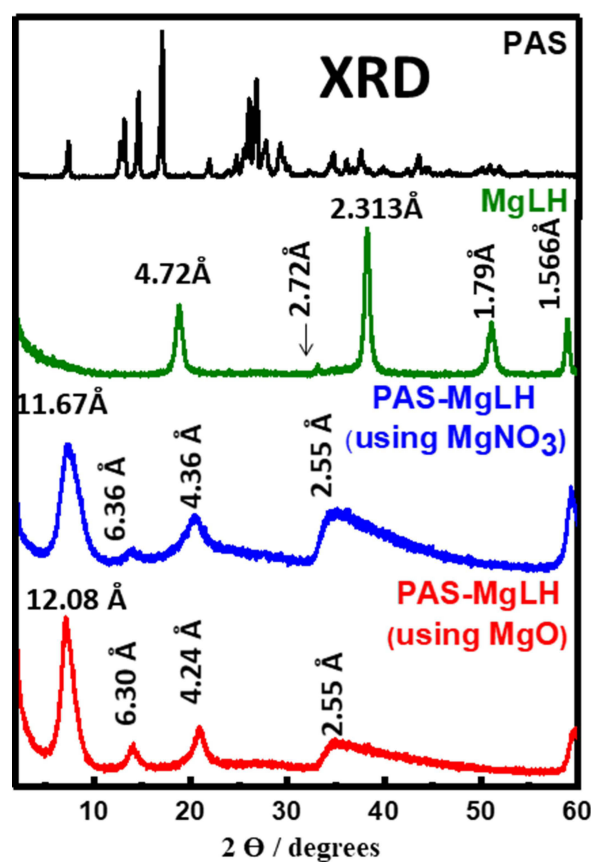

B

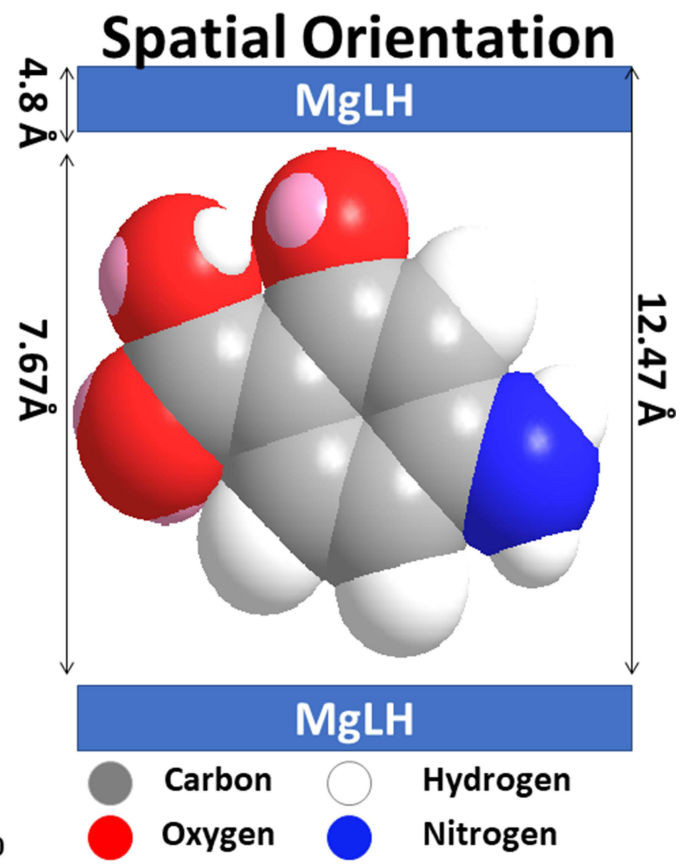

Figure I X-ray diffraction patterns of Nanocomposite-A (red), Nanocomposite-B, MgLH and PAS free drug (A) and the spatial orientation of PAS into the MgLH interlayer gallery (B). 
and $2.9 \AA$, respectively. ${ }^{50}$ By subtracting the inorganic layer thickness of $4.8 \AA$ from the average basal spacing value of $12.47 \AA$ and $12.49 \AA$, the obtained value is $7.67 \AA$ and $7.69 \AA$ for Nanocomposite-A and Nanocomposite-B, respectively. These remaining values of $7.67 \AA$ and $7.69 \AA$ are near to the horizontal molecular orientation (Y-axis) which is $7.1 \AA$ for PAS. This suggests that PAS was oriented in the horizontal form between the interlayer galleries of $\mathrm{MgLH}$ with a slightly tilted orientation in both nanocomposites. This tilted form is more favorable for the electrostatic interaction and the formation of hydrogen bonds between PAS and the host, MgLH. Figure 1B shows the orientation of PAS in Nanocomposite-A, and a similar orientation of PAS in Nanocomposite-B is expected.

\section{Infrared Spectroscopy}

Infrared spectroscopy was used as supporting evidence for the successful intercalation of anions into metal hydroxide nanolayers. In addition to XRD analysis, the intercalation of PAS was further supported by Fourier Transformed Infrared (FTIR) spectroscopy. Figure 2 shows the FTIR spectra of the free drug (PAS), magnesium layered hydroxides (MgLH), Nanocomposite-A and Nanocomposite-B. The FTIR spectrum of free PAS shows characteristics of the PAS functional group absorption bands, such as $\mathrm{O}-\mathrm{H},=\mathrm{C}-\mathrm{H}$, and $\mathrm{N}-\mathrm{H}$ at high wavenumbers, characteristic carbonyl $(\mathrm{C}=\mathrm{O})$ bands for the carboxylic acid group at $1609 \mathrm{~cm}^{-1}$, aromatic ring C-C bond at 1529 and $1433 \mathrm{~cm}^{-1}$ and the characteristic alcohol peaks, C-O and $\mathrm{O}-\mathrm{H}$ at $1273 \mathrm{~cm}^{-1}$ and $1190 \mathrm{~cm}^{-1}$, respectively. ${ }^{51-53}$ Non-intercalated MgLH shows only a few absorption bands due to the hydroxyl group at 3694 $\mathrm{cm}^{-1}$ and the lattice vibration for the $\mathrm{Mg}-\mathrm{O}$ absorption band at $1419 \mathrm{~cm}^{-1}$ and $1010 \mathrm{~cm}^{-1} \cdot 54,55$ The FTIR spectra of both of the nanocomposites (A and B) show the absorption bands of the PAS together with bands for $\mathrm{MgLH}$, which strongly support the XRD result for the successful intercalation of PAS into MgLH. Detailed absorption bands of free PAS and both of the nanocomposites (A and B) are given in Table $1.48,51,54,56$

\section{HPLC, ICP and TGA Analyses}

The presence of magnesium, which is the major component of $\mathrm{MgLH}$, was determined using ICP analysis and was found to be about $45 \%$ in both nanocomposites (A and B). Drug (PAS) loading was determined by high-performance liquid chromatography (HPLC) using

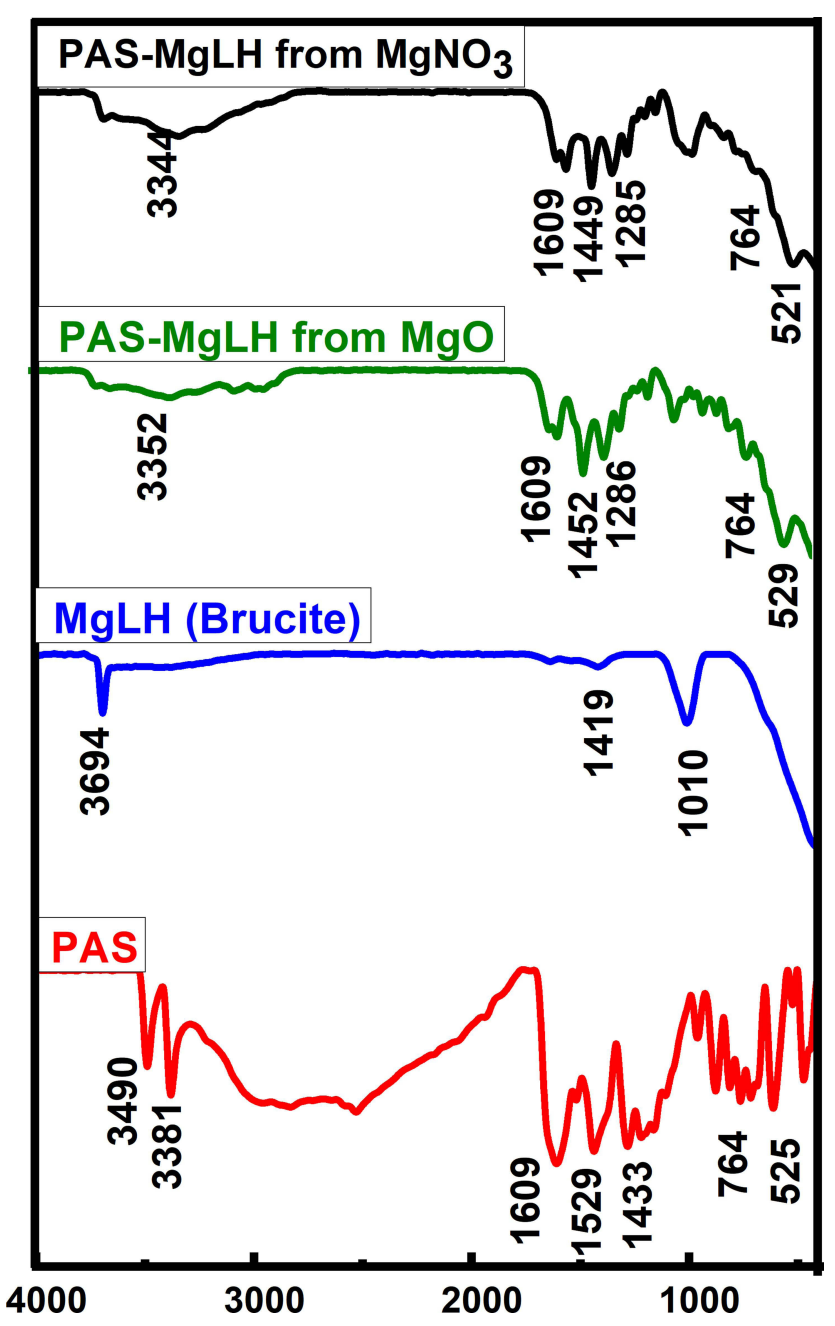

Figure 2 FTIR Spectra of PAS, MgLH, and its nanocomposites.

a previously developed protocol. ${ }^{57}$ The loading of PAS was found to be about $23 \%$ and $22 \%$ in Nanocomposite-A and Nanocomposite-B, respectively. In the thermal analysis, $15 \%$ and $11 \%$ weight loss occurred at about $50{ }^{\circ} \mathrm{C}$ for the Nanocomposite-A and Nanocomposite-B, respectively, which can be attributed to the physically adsorbed water molecules on the surface of the nanocomposites. The empirical formula was determined using drug loading, ICP-OES and TGA analysis for both the nanocomposites and is as given below.

Nanocomposite A: $\left[\mathrm{Mg}_{1.88}(\mathrm{OH})_{2}\right] \cdot\left(\mathrm{C}_{7} \mathrm{H}_{6} \mathrm{NO}_{3}\right)_{0.15} \cdot 0.83 \mathrm{H}_{2} \mathrm{O}$

Nanocomposite B: $\left[\mathrm{Mg}_{1.87}(\mathrm{OH})_{2}\right] \cdot\left(\mathrm{C}_{7} \mathrm{H}_{6} \mathrm{NO}_{3}\right)_{0.14} \cdot 0.61 \mathrm{H}_{2} \mathrm{O}$

\section{Transmission Electron Microscopy and Particle Size Distribution Studies}

The transmission electron micrographs (TEM) revealed that the nanocomposite particles were well dispersed with a 
Table I FTIR Assignments (in nm) of PAS and Its Nanocomposites (A and B)

\begin{tabular}{|c|c|c|c|}
\hline Assignment & PAS & Nanocomposite-A & Nanocomposite-B \\
\hline$v$ as $(\mathrm{N}-\mathrm{H})$ & 3490 & \multirow{2}{*}{$\begin{array}{l}\text { Overlapped with O-H stretching at } \\
3352\end{array}$} & \multirow{2}{*}{$\begin{array}{l}\text { Overlapped with O-H stretching at } \\
3344\end{array}$} \\
\hline$v s(\mathrm{~N}-\mathrm{H})$ & 3381 & & \\
\hline$v(\mathrm{O}-\mathrm{H})$ in the layer $/ \mathrm{H}_{2} \mathrm{O}$ & 3694 & 3352 & 3344 \\
\hline$v(\mathrm{C}=\mathrm{O})$ in $\mathrm{COOH}$ & 1609 & 1609 & 1609 \\
\hline$v \mathrm{O}-\mathrm{H}$ ring stretching & $\begin{array}{l}3020,1283 \\
1163\end{array}$ & 1286 & 1285 \\
\hline $\begin{array}{l}v(\mathrm{C}-\mathrm{C}) \text { assym and sym: stretching of aromatic } \\
\text { ring }\end{array}$ & 1519,1433 & 1452 & 1449 \\
\hline$v$ aromatic $(\mathrm{C}-\mathrm{C}-\mathrm{C})$ ring sym bending & 525 & 529 & 521 \\
\hline
\end{tabular}

uniform circular shape as shown in Figure 3A and B, for the Nanocomposite-A and Nanocomposite-B, respectively. The particle size and size distribution were determined from the
TEM micrographs using UTHSCSA Image Tool software. About 105 different particles $(\mathrm{N})$ were randomly selected for each nanocomposite and their diameters were measured using

\section{TEM of Nanocomposite A}
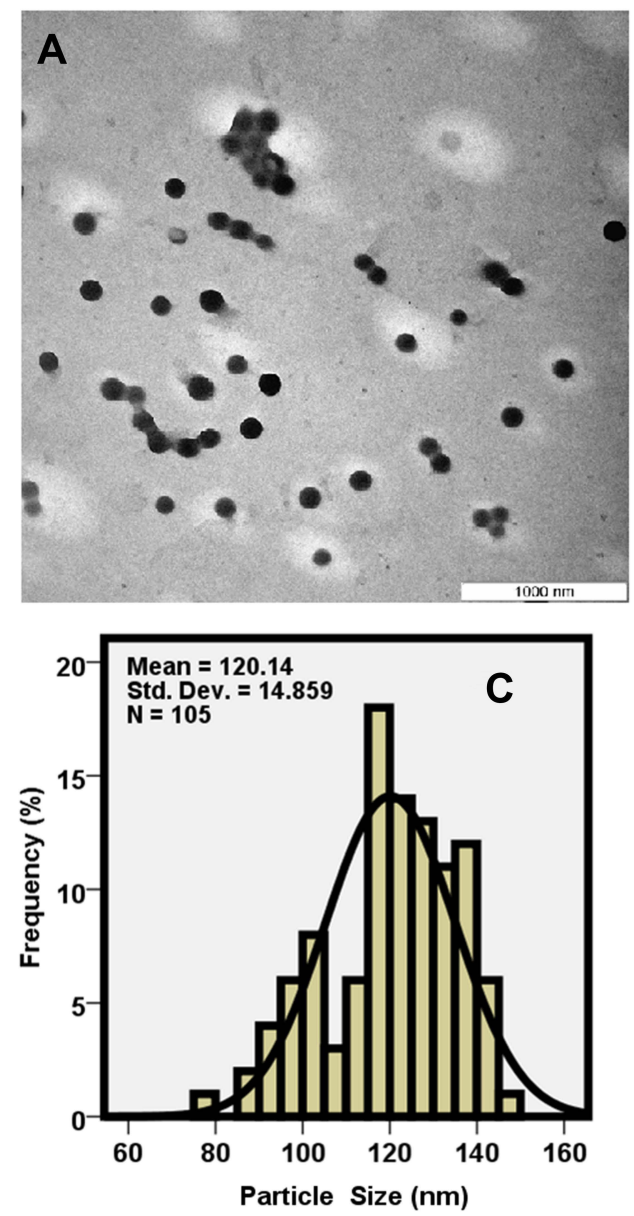

TEM of Nanocomposite B
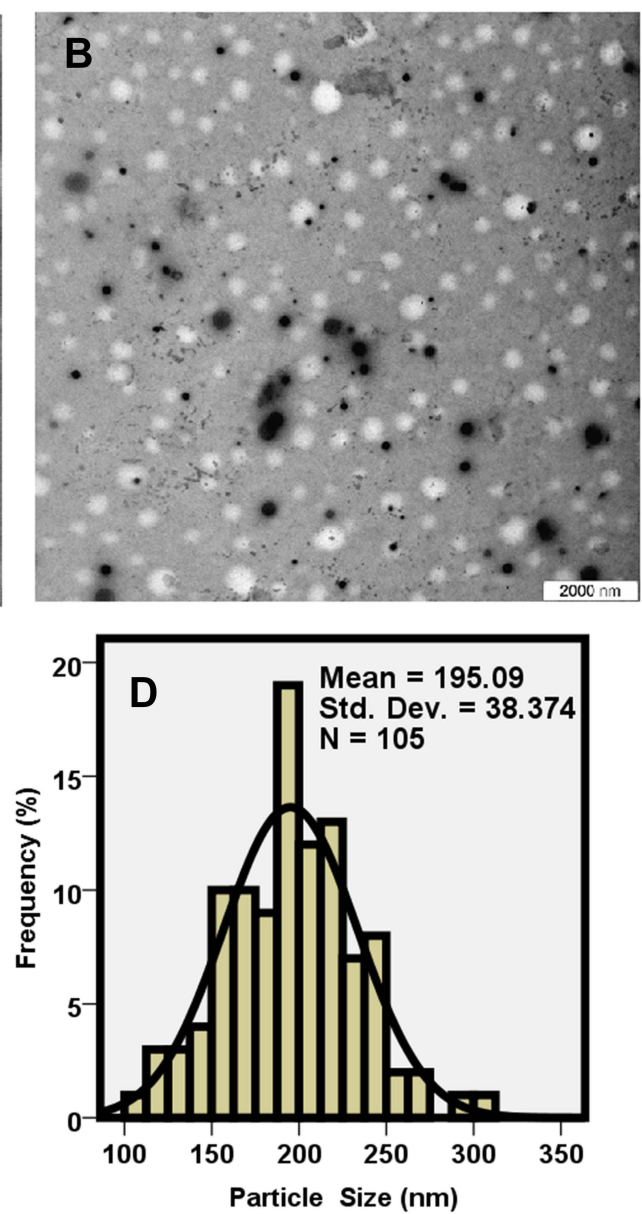

Figure 3 Transmission electron micrographs of Nanocomposite-A (A), Nanocomposites-B (B) and particle size distribution of Nanocomposite-A (C) and Nanocomposite-B (D). 
the software. The average diameter in Nanocomposite-A was found to be $120 \mathrm{~nm}$ with a particle size distribution of 70-150 $\mathrm{nm}$. For the Nanocomposite-B, the average diameter was determined to be $195 \mathrm{~nm}$ with an overall particle size distribution of $100-300 \mathrm{~nm}$. Figure 3C and D show the particle diameter and particle size distribution of Nanocomposite-A and Nanocomposite-B, respectively.

\section{Dynamic Light Scattering (DLS) Analysis}

The particle size of both of the nanocomposites was determined using DLS analysis using a zeta sizer. The particle size distribution of Nanocomposite-A was found to be in the range of $50 \mathrm{~nm}$ to $600 \mathrm{~nm}$. According to the cumulative distribution frequency, $80 \%$ of the particles were found to be equal to or less than $142 \mathrm{~nm}$ as shown in Figure 4A. The particle distribution for the Nanocomposite-B was found to be $150 \mathrm{~nm}$ to $600 \mathrm{~nm}$. According to the cumulative distribution frequency for the Nanocomposite-B, $80 \%$ of the particles were found to be equal to or less than $220 \mathrm{~nm}$ as shown in Figure 4B. The overall particle size distribution was found to be larger than the TEM particle size distribution which can be ascribed to the hydrodynamic size and agglomeration/accumulation of the particles in an aqueous solution. ${ }^{58}$

\section{In vitro Release Study}

The in vitro release of PAS from the Nanocomposite-A and Nanocomposite-B were carried out in human body simulated phosphate buffer saline (PBS) solutions of $\mathrm{pH}$ 7.4 and 4.8. Figures $5 \mathrm{~A}$ and $\mathrm{B}$ show the in vitro release profiles of PAS from the Nanocomposite-A in a PBS

A

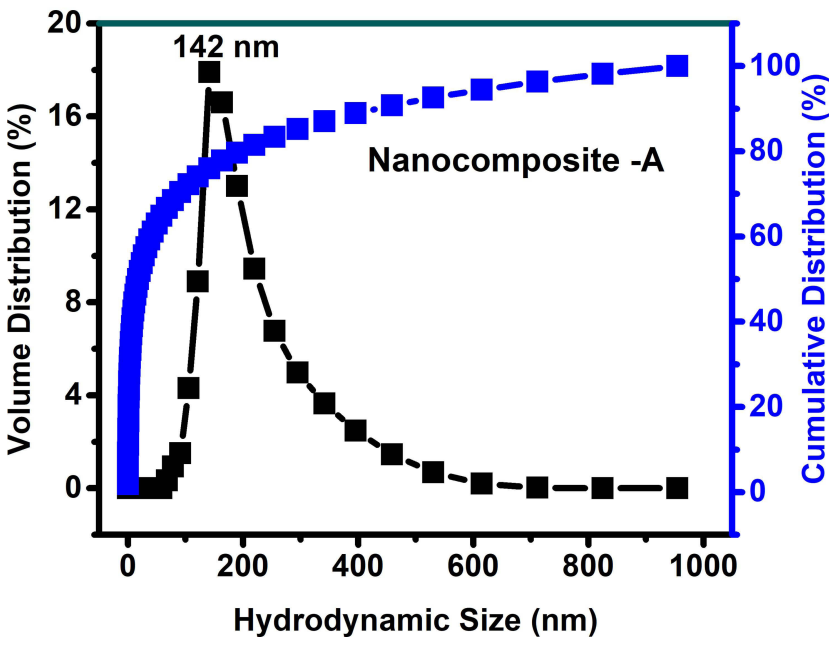

solution of $\mathrm{pH} 7.4$ and $\mathrm{pH} 4.8$, respectively. Under both in vitro conditions, PAS took about 1400 minutes for about a $100 \%$ release. PAS took almost the same time (ie, 1400 minutes) to be $100 \%$ released, as it took for Nanocomposite-A. The release behavior of PAS from both nanocomposites was found to be sustained without any sign of burst release, which is most commonly found in the release of the drugs from their layered double hydroxide galleries. ${ }^{27,50}$ The release duration of $1400 \mathrm{~min}$ utes, or almost 24 hours, indicated that the PAS concentration could be possibly maintained in the human body for 24 hours by the designed nanodelivery formulation. This will significantly improve the bioavailability of PAS, which will certainly improve the therapeutic efficacy.

\section{Antimicrobial Susceptibility Tests}

The synthesized nanocomposites showed antimycobacterial activity as shown in Figure 6. The MICs of the Nanocomposites (A and B) were found to be $15.4 \mu \mathrm{g} / \mathrm{mL}$ and $20.1 \mu \mathrm{g} / \mathrm{mL}$, respectively compared to the free drug, PAS, which was $5.5 \mu \mathrm{g} / \mathrm{mL}$. The percent loading of PAS in Nanocomposite-A and Nanocomposite-B was found to be $23 \%$ and $22 \%$, respectively. Based on the percent loading of PAS, the amount of PAS in the Nanocomposite-A and Nanocomposite-B was found to be $3.45 \mu \mathrm{g} / \mathrm{mL}$ and 4.42 $\mu \mathrm{g} / \mathrm{mL}$, respectively, which is termed as the effective MIC. Therefore, the effective MICs for the nanocomposites were relatively smaller compared to the free drug, PAS, which was $5.5 \mu \mathrm{g} / \mathrm{mL}$, suggesting an improved therapeutic efficacy of the nanocomposites.

B

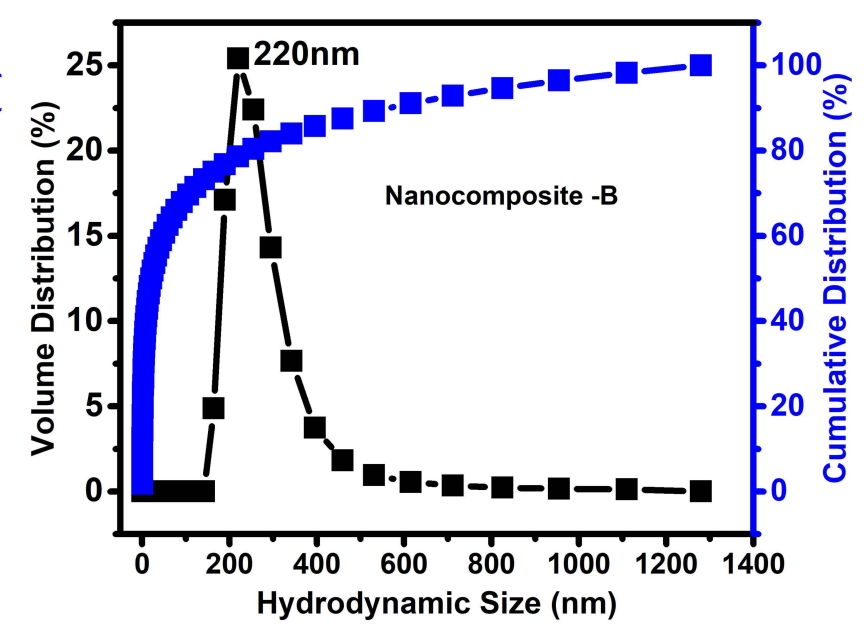

Figure 4 (A and B) show the hydrodynamic size for Nanocomposite-A and Nanocomposite-B, respectively. 
A

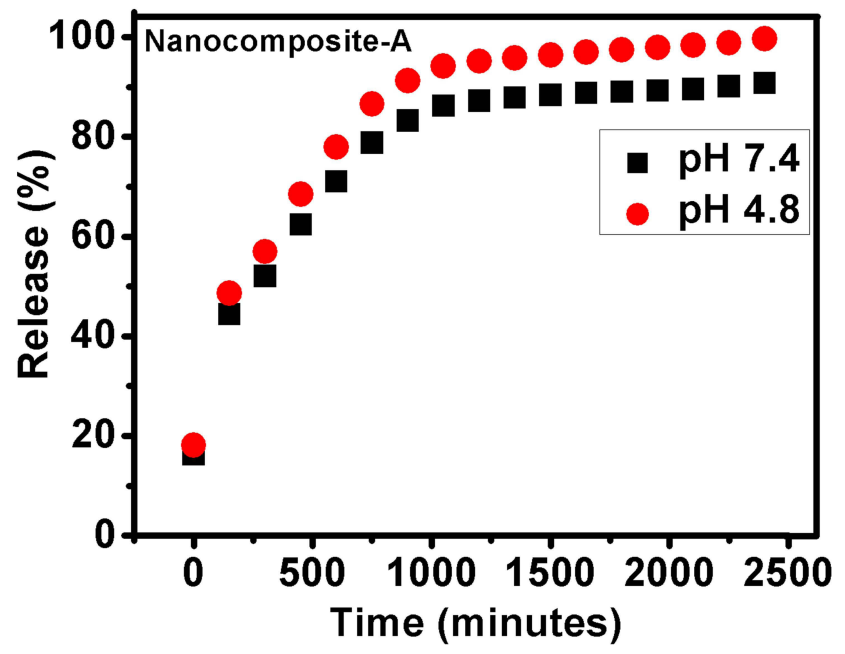

B

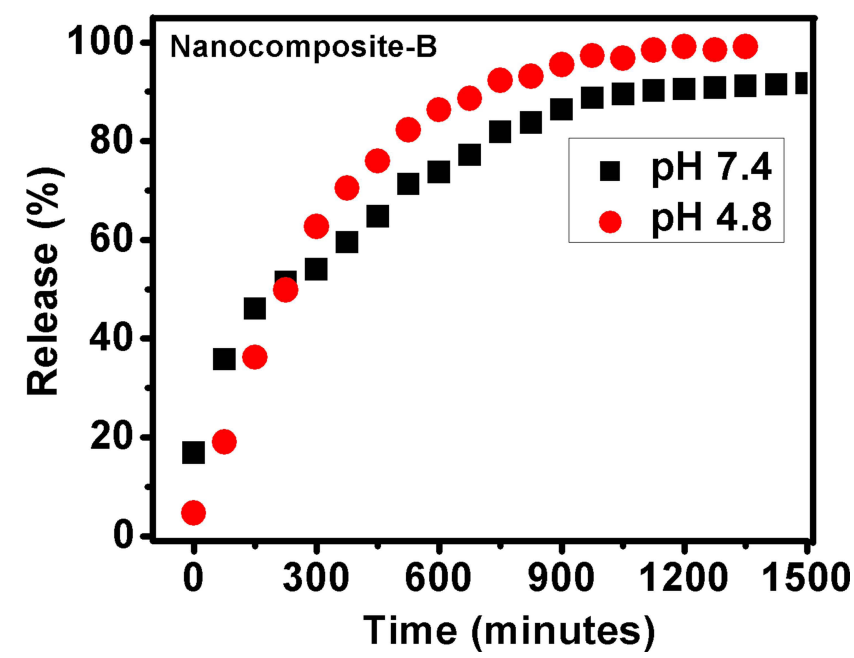

Figure 5 In vitro release of PAS from nanocomposite-A $(\mathbf{A})$ and nanocomposite-B $(\mathbf{B})$ in phosphate buffer saline solutions of $\mathrm{pH} 7.4$ and $\mathrm{pH} 4.8$.

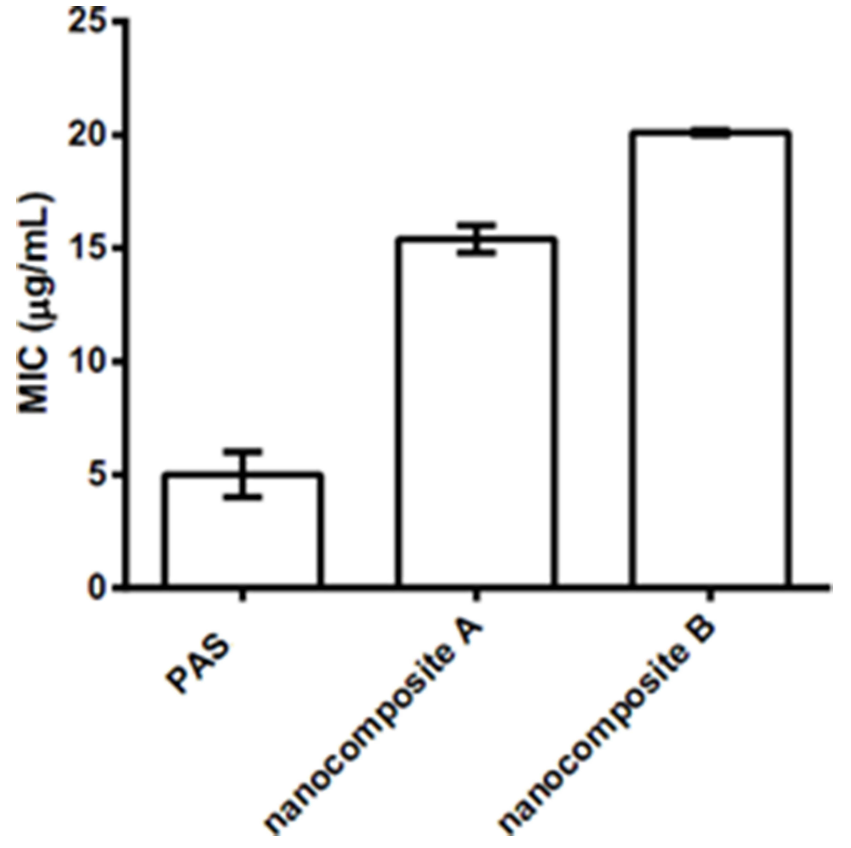

Figure 6 Minimum inhibitory concentrations ( $\mu \mathrm{g} / \mathrm{mL}$ ) (MICs) of the PAS nanocomposites as compared to the PAS free drug against Mycobacterium tuberculosis as determined using the Mycobacteria Growth Indicator Tube (MGIT) with BACTEC MGIT 960 growth supplement for drug susceptibility testing and measured by the MGIT 960 instrument (Becton Dickinson Diagnostic Systems, Sparks, MD, USA).

\section{Antimicrobial Results}

The results of the antimicrobial testing using growth kinetics showed that the PAS nanocomposites (A and B) have antibacterial activity against Gram-positive bacteria (S. aureus), Gram-negative bacteria (E. coli), and antifungal activity against Candida albicans, as shown in Figure 7A and $\mathrm{B}$. This additional antibacterial activity of the PAS nanocomposites as compared to the free PSA, which lacks antimicrobial activity, is advantageous in the treatment of polymicrobial infections that might be associated with tuberculosis infections.

\section{Cytotoxicity Studies}

To evaluate the cytotoxicity profile, the free drug PAS, empty carrier (MgLH) and designed anti-TB nanocomposites (A and B) were treated with 3T3 and MRC-5 cells. The different concentrations, ie, $1.56 \mu \mathrm{g} / \mathrm{mL}$ to $100 \mu \mathrm{g} /$ $\mathrm{mL}$, of the samples were incubated for 72 hours with these cell lines. As shown in Figure 8A and B, more than 80\% viability of both cell lines was measured at the highest concentration of $100 \mu \mathrm{g} / \mathrm{mL}$ and after 72 hours of incubation. These results suggest good cytocompatibility of the designed anti-TB nanocomposites.

\section{Effect of the Nanocomposites on RAW 264.7 Macrophage Viability}

Cell viability was investigated by MTT assays after treatment with the nanocomposites, free drug PAS, and pristine empty MgLH. As shown in Figure 9, at the higher concentration of the nanocomposites, pure drugs and carriers showed a cytotoxic effect on macrophages. However, at lower concentrations of nanoparticles, carrier and pure drugs did not show any significant cell cytotoxicity, at least up to $25 \mu \mathrm{g} / \mathrm{mL}$. Therefore, we have selected nontoxic concentrations (at $10 \mu \mathrm{g} / \mathrm{mL}$ ) of the nanocomposites, drugs and carriers for further in vitro biological experiments. 

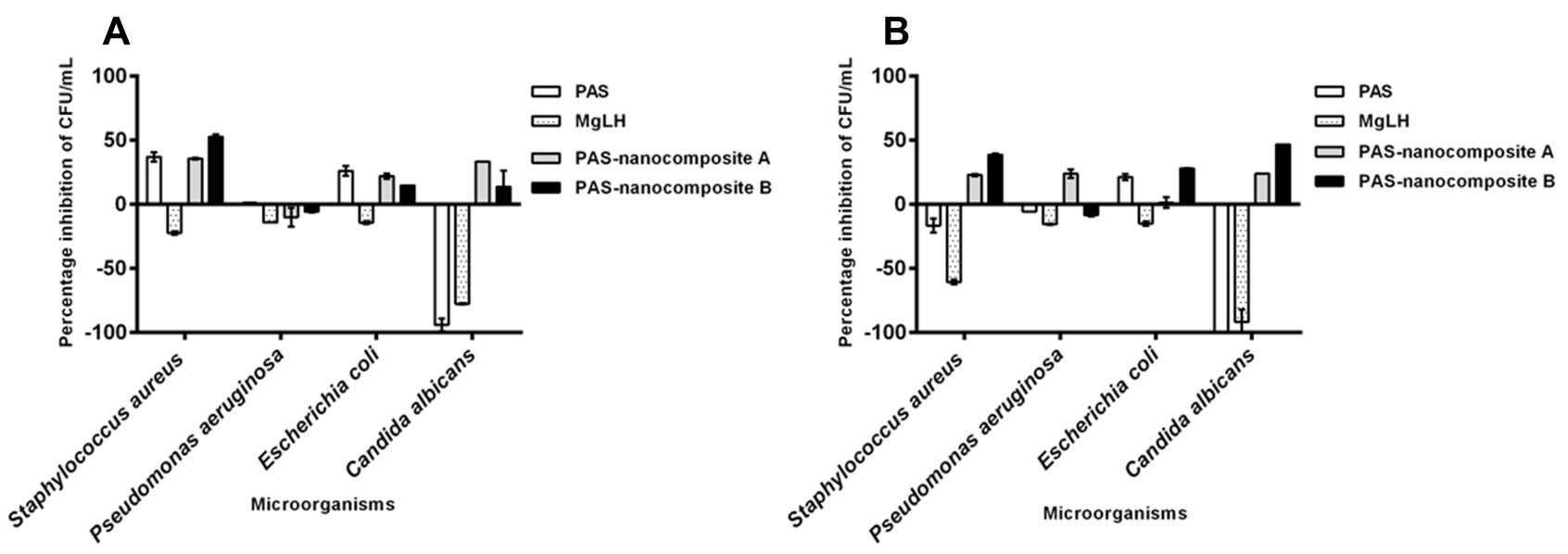

Figure 7 Antimicrobial effects of PAS free drug and PAS nanocomposites, Nanocomposite-A and Nanocomposite-B against different microorganisms, showing the inhibition of microbial growth using the plate colony-forming unit (CFU) counting method at two different concentrations: (A) I mg and (B) $2 \mathrm{mg}$.

Effect of the Nanocomposites on Lipopolysaccharide Stimulated Production of Pro-Inflammatory Molecules in RAW 264.7 Cells

The inflammatory process involves various immune cells, mainly monocytes, macrophages and dendritic cell activation. Among all of the cells, macrophages are more sensitive and known to play a crucial role in normal defensive reactions and to release the numerous inflammatory mediators by the induction of inflammatory cytokines and microbial substances, such as lipopolysaccharides (LPSs). ${ }^{59}$ Most biomedical researchers have investigated the anti-inflammatory potential of compounds using LPS induced in vitro and in vivo experimental models particularly with macrophages and monocytes. ${ }^{59}$

LPS-stimulated macrophages induce numerous cellular events, such as the production of key inflammatory mediators which include NO, IL-6, IL- $1 \beta$ and TNF- $\alpha$, and the production of these inflammatory molecules in the cell culture media or serum of LPS-induced macrophages or experimental animals, which are consistent markers of inflammation. ${ }^{60}$ Based on these inflammatory events, we hypothesized that suppression of these inflammatory mediators in LPS stimulated macrophages may serve as the foundation for potential drug development against various inflammatory-associated diseases. Hence, in this investigation, the anti-inflammatory effects of the samples were evaluated on LPS stimulated macrophages, RAW 264.7 cells. Dexamethasone, a plant-derived compound, was used as a positive control for all the experiments and doses of positive control drugs were followed according to previous findings. ${ }^{61,62}$
NO and other pro-inflammatory cytokines, including IL6 , IL-1 $\beta$ and TNF- $\alpha$, are some of the key inflammatory mediators in numerous vital organs. ${ }^{63}$ In the present study, we investigated the effect of nanocomposites, drugs and carriers on the production of NO, IL-6, IL- $1 \beta$ and TNF- $\alpha$ in LPS induced RAW 264.7 cells. As depicted in Figures 10 and 11A-C, LPS alone significantly increased the level of NO production when compared to the control, without any treatment. In Figure 11, the nanocomposites, carriers and pure drugs showed a significant inhibitory effect on NO production in LPS-stimulated RAW 264.7 cells. However, in the production of pro-inflammatory cytokines, Nanocomposite B seemed to show a better significant inhibitory effect when compared to Nanocomposite A, the carrier and pure drugs in LPS stimulated macrophages. These inhibitory effects of the nanocomposites were comparable with the positive control drug, dexamethasone.

\section{Discussion}

The layered double hydroxide is a unique nanomaterial vastly used in various fields such as environmental remediation, catalysis, flame retardants, antimicrobial clay materials, cosmetics, biosensors, bioimaging, gene delivery, bioimplants and drug delivery carriers, etc. ${ }^{11,64-66}$ Layered double hydroxides are composed of divalent ions (Mg(II), Zn (II), Fe (II), Ni (II)) and trivalent ions (Al (III), Fe (III), Gd (III)) and both are combined to create a positive charge in the structure, making the material suitable for anions, drugs and species with a lone pair of electrons. ${ }^{12,16,67}$ The other variation of the materials includes divalent layered structures such as zinc layered hydroxides which is the most common example and for this type of 

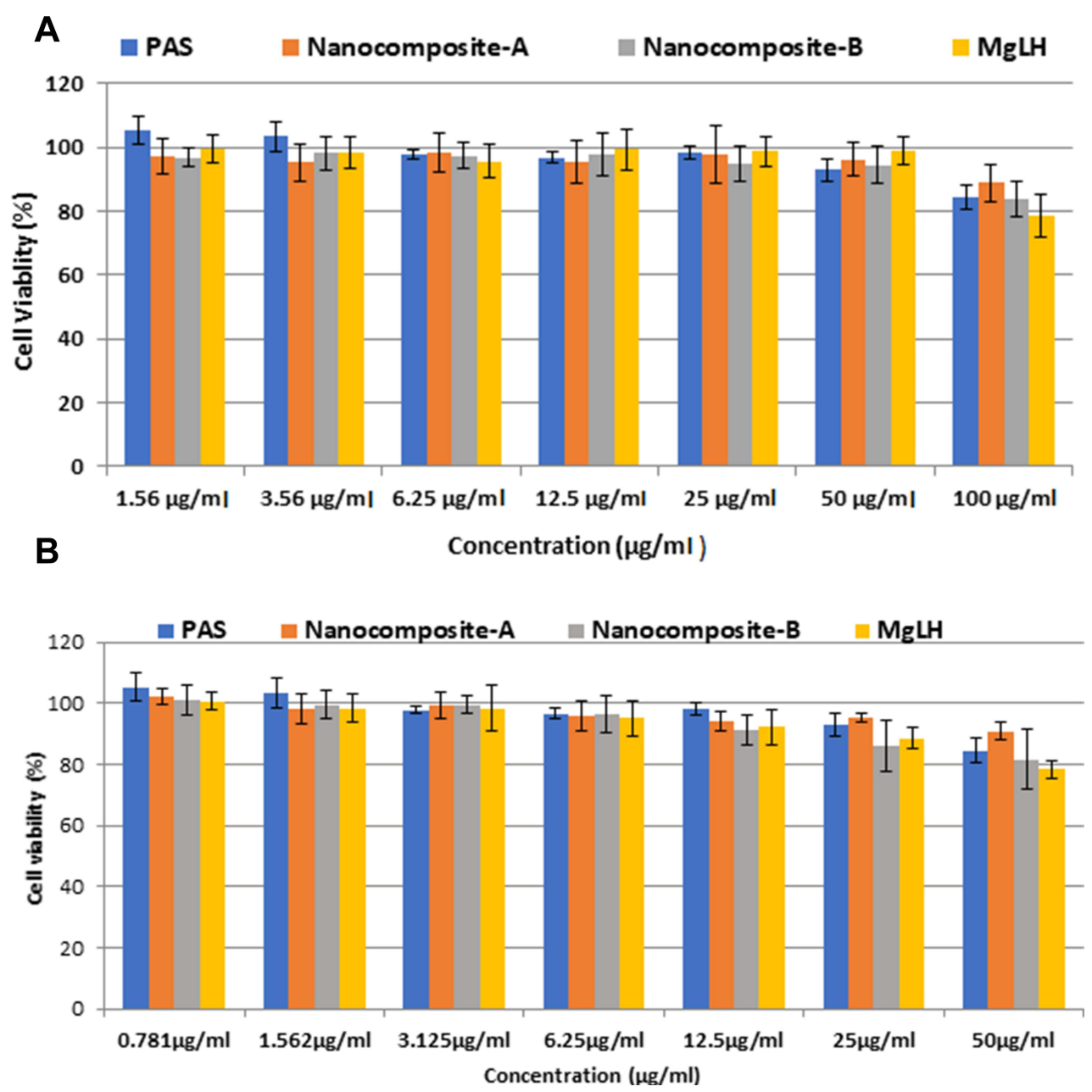

Figure 8 (A) Incubation of 3T3 cells after 72 hours up to a concentration of $100 \mu \mathrm{g} / \mathrm{mL}$. (B) Incubation of human normal lung MRC-5 cells in the presence of the nanocomposite after 72 hours.

material, no trivalent ion is added ${ }^{68,69}$ In this study, we report for the first time, the synthesis of magnesium layered hydroxide nanomaterials, $\mathrm{MgLH}$, using the co-precipitation method from magnesium nitrate and magnesium oxide as the starting material. The anti-tuberculosis drug, para-aminosalicylic acid (PAS), was successfully intercalated into the interlayers. The resulting MgLH-PAS material was characterized in detail using XRD, FTIR, TEM, TGA, HPLC and ICP-AES, etc., and the results were described in each section above.

The size of the nanocomposites was determined from their TEM micrographs using image $\mathrm{J}$ software through the calculation of randomly selected nanoparticles. The particles were distributed in the range of $70-150 \mathrm{~nm}$ with an average size of $120 \mathrm{~nm}$ for the NanocompositeA. For the Nanocomposite-B, the particle size distribution was found to be between 100 and $300 \mathrm{~nm}$ with the average size of $195 \mathrm{~nm}$. The hydrodynamic size was determined using DLS analysis. The hydrodynamic size was found to be in the range of $50 \mathrm{~nm}$ to $600 \mathrm{~nm}$ with the mean particle size of $142 \mathrm{~nm}$ for the Nanocomposite-A and according to the cumulative frequency distribution, more than $80 \%$ of nanoparticles were equal to or less than $142 \mathrm{~nm}$ in size. The particle size distribution for the Nanocomposite-B was found to be $150 \mathrm{~nm}$ to $600 \mathrm{~nm}$ with a mean particle size of $220 \mathrm{~nm}$ and the cumulative distribution frequency suggested that $80 \%$ of the nanoparticles were equal to or less than $220 \mathrm{~nm}$. The greater hydrodynamic size can be attributed to the accumulation/agglomeration of nanoparticles in an aqueous solution. The release of the active, anti-TB drug, PAS, was found to be sustained for 24 hours without any burst release in the human body simulated PBS buffer solution. This designed MgLH-PAS nano-formulation was tested for its anti-TB assays against Mycobacterium tuberculosis bacteria and the effective 


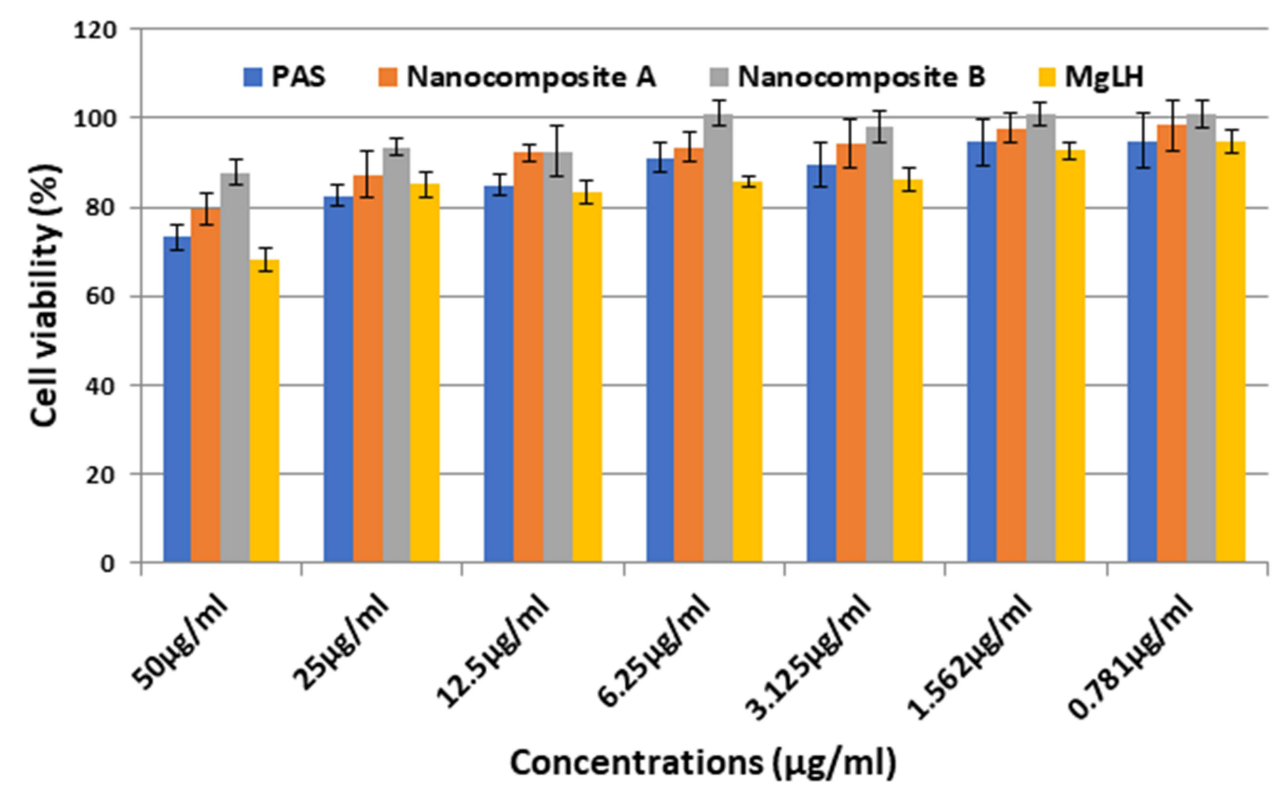

Figure 9 Effects of nanoparticles on RAW 264.7 macrophage viability. Macrophages at a cell density of $1 \times 10^{4}$ cells/well were seeded in a 96 well plate and treated with the indicated nanoparticle concentrations for $24 \mathrm{~h}$. The data are presented as mean \pm SD of three independent experiments.

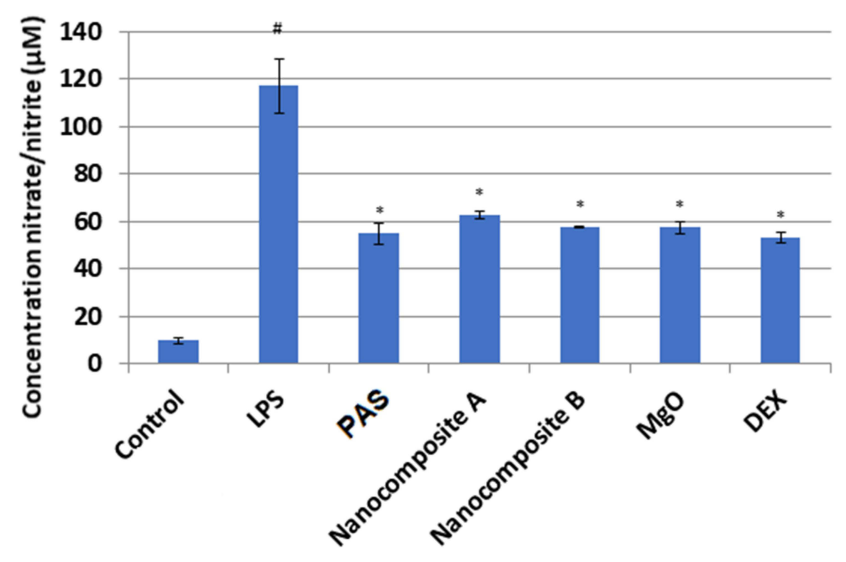

Figure 10 Effects of nanoparticles on NO production in LPS- induced RAW 264.7 macrophages. Macrophages at a cell density of $1 \times 10^{6}$ cells/well in the presence or absence of LPS were seeded in a 6 well plate and treated with the indicated concentrations of nanoparticles and dexamethasone for $24 \mathrm{~h}$. The supernatants were collected and investigated by the Griess assay. The data are presented as mean $\pm S D$ of three independent experiments. The control is the base level of nitrite released without LPS induction. ${ }^{\#} p<0.001$ LPS-treated group vs Control and $*_{p}<$ 0.01 treated group significantly different from LPS-treated group.

MIC was found to be $3.45 \mu \mathrm{g} / \mathrm{mL}$ and $4.42 \mu \mathrm{g} / \mathrm{mL}$ for Nanocomposite-A and Nanocomposite-B, respectively compared to PAS which was $5.5 \mu \mathrm{g} / \mathrm{mL}$, suggesting improved efficacy of the later. The nanocomposites also have antimicrobial properties against gram-positive and gram-negative bacteria. In addition, the cytotoxicity profile of the samples was checked on normal cells namely $3 \mathrm{~T} 3$ fibroblast cells and MRC-5 lung normal cells. The samples showed good biocompatibility with these cell lines. TB infection causes inflammation at the site of infection and the anti-inflammatory properties of the designed nanocomposites can be very helpful in the treatment of tuberculosis resulting in better therapeutic outcomes.

\section{Conclusion}

In this study, a novel MgLH delivery system was synthesized for the first time using the coprecipitation method with $\mathrm{MgNO}_{3}$ and $\mathrm{MgO}$ as starting reagents for the delivery of an anti-TB drug, PAS. The designed nanocomposites were characterized in detail using XRD, FTIR, TEM, HPLC and ICP analyses. The average hydrodynamic sizes of the nanocomposites (A and B) were found to be $220 \mathrm{~nm}$ and $142 \mathrm{~nm}$, respectively. The release of PAS from both the Nanocomposite-A and B was found to be sustained in the human body simulated PBS solutions of $\mathrm{pH}$ 7.4 and $\mathrm{pH}$ 4.8. The nanodelivery formulation (PAS$\mathrm{MgLH})$ was found to show good antimycobacterial and antimicrobial activities, significant anti-inflammatory effects on the suppression of LPS stimulated inflammatory mediators in RAW 264.7 macrophages, and most importantly, it was found to be biocompatible with human MRC5 and 3T3 cells. The synergistic anti-inflammatory action of the designed nano-formulation will prevent severe local inflammatory reactions associated with Mycobacterium tuberculosis infections. These in vitro results are highly encouraging for further in vivo evaluation. 


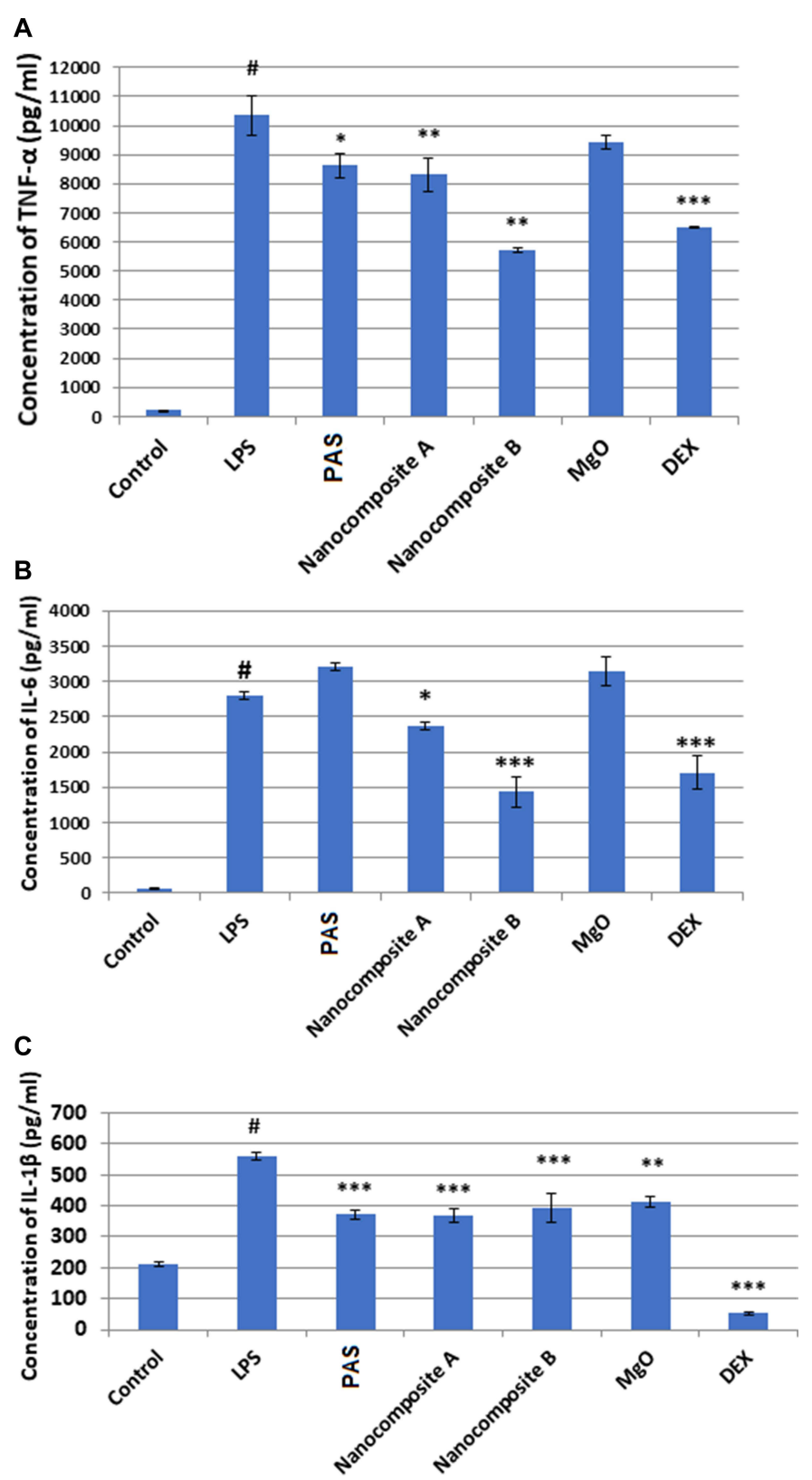

Figure II (A-C) Effect of nanoparticles on the production of the cytokines TNF- $\alpha$, IL-6 and IL-I $\beta$ in LPS- induced RAW 264.7 macrophages. A density of I $\times 10^{6}$ cells/ well of macrophages induced by LPS was seeded in 6 well plates and treated with the indicated concentrations of a flower extract and dexamethasone for $24 \mathrm{~h}$. The supernatants were collected and analyzed by ELISA kits. The data are presented as the mean \pm SD of three independent experiments. \#p<0.00I, LPS-treated group vs Control, $* * * p<0.001, * * p<0.01$ and $* p<0.05$ treated group significantly different from the LPS-treated group. Control is the basal level of cytokines released without LPS induction.

\section{Acknowledgment}

The authors would like to thank Dr Benjamin M. Geilich from the Department of Chemical Engineering, Department of Bioengineering, Northeastern University, Boston, MA, USA for his help in the antimicrobial testing experiments.

\section{Funding}

The study was funded in part by funds from the Universiti Putra Malaysia and the Ministry of Higher Education of
Malaysia (grant UPM/800-3/3/1/GBP/2019/9678800) and Northeastern University, USA.

\section{Disclosure}

The authors report no conflicts of interest for this work.

\section{References}

1. World Health Organization. Global Tuberculosis Report 2020. Geneva: World Health Organization; 2020. 
2. Hafkin J, Hittel N, Martin A, Gupta R. Early outcomes in MDR-TB and XDR-TB patients treated with delamanid under compassionate use. Eur Respir J. 2017;50(1):1700311. doi:10.1183/13993003.00311-2017

3. Press W. Treatment of Tuberculosis Guidelines. 4th ed. WHO/HTM/ TB/2009.420. 20 Avenue Appia, 1211 Geneva 27, Switzerland: World Health Organization; 2010.

4. Liu CH, Liu H, Ge B. Innate immunity in tuberculosis: host defense vs pathogen evasion. Cell Mol Immunol. 2017;14(12):963-975. doi:10.1038/cmi.2017.88

5. Baguma R, Mbandi SK, Rodo MJ, et al. Inflammatory determinants of differential tuberculosis risk in pre-adolescent children and young adults. Front Immunol. 2021;12:639965. doi:10.3389/ fimmu.2021.639965

6. Hayford FEA, Dolman RC, Blaauw R, et al. The effects of antiinflammatory agents as host-directed adjunct treatment of tuberculosis in humans: a systematic review and meta-analysis. Respir Res. 2020;21(1):223. doi:10.1186/s12931-020-01488-9

7. Toossi Z. The inflammatory response in Mycobacterium tuberculosis infection. Arch Immunol Ther Exp (Warsz). 2000;48(6):513-519.

8. Tomić M, Micov A, Pecikoza U, Stepanović-Petrović R. Chapter 1 clinical uses of nonsteroidal anti-inflammatory drugs (NSAIDs) and potential benefits of NSAIDs modified-release preparations. In: Čalija B, editor. Microsized and Nanosized Carriers for Nonsteroidal AntiInflammatory Drugs. Boston: Academic Press; 2017:1-29.

9. Krajišnik D, Čalija B, Cekić N. Chapter 2 - polymeric microparticles and inorganic micro/nanoparticulate drug carriers: an overview and pharmaceutical application. In: Čalija B, editor. Microsized and Nanosized Carriers for Nonsteroidal Anti-Inflammatory Drugs. Boston: Academic Press; 2017:31-67.

10. Saifullah B. Inorganic nanolayers: structure, preparation, and biomedical applications. Int J Nanomedicine. 2015;10:24.

11. Yan L, Gonca S, Zhu G, Zhang W, Chen X. Layered double hydroxide nanostructures and nanocomposites for biomedical applications. J Mater Chem B. 2019;7(37):5583-5601. doi:10.1039/C9TB01312A

12. Wijitwongwan RP, Intasa-ard S, Ogawa M. Preparation of layered double hydroxides toward precisely designed hierarchical organization. ChemEngineering. 2019;3(3):22. doi:10.3390/chemengineering3030068

13. Laipan M, Yu J, Zhu R, et al. Functionalized layered double hydroxides for innovative applications. Mater Horiz. 2020;7(3):715-745.

14. Liu JC, Qi B, Song YF. Engineering polyoxometalate-intercalated layered double hydroxides for catalytic applications. Dalton Trans. 2020;49(13):3934-3941.

15. Bullo Saifullah PA. Development of a biocompatible nanodelivery system for tuberculosis drugs based on isoniazid-Mg/Al layered double hydroxide. Int J Nanomedicine. 2014;9:14.

16. Yazdani P, Mansouri E, Eyvazi S, et al. Layered double hydroxide nanoparticles as an appealing nanoparticle in gene/plasmid and drug delivery system in $\mathrm{C} 2 \mathrm{C} 12$ myoblast cells. Artif Cells, Nanomed Biotechnol. 2019;47(1):436-442. doi:10.1080/21691401.2018.1559182

17. Abo El-Reesh GY, Farghali AA, Taha M, Mahmoud RK. Novel synthesis of $\mathrm{Ni} / \mathrm{Fe}$ layered double hydroxides using urea and glycerol and their enhanced adsorption behavior for $\mathrm{Cr}(\mathrm{VI})$ removal. Sci Rep. 2020;10(1):587. doi:10.1038/s41598-020-57519-4

18. Bohn T. Magnesium Absorption in Humans. Germany: University Frankfurt; 2003.

19. Wester PO, Dyckner T. The importance of the magnesium ion. Magnesium deficiency symptomatology and occurrence. Acta Med Scand Suppl. 1998;661:2.

20. Brady H. Magnesium: the forgotten cation. Ir Med J. 1982;80:4.

21. Severino P, Netti L, Mariani MV, Maraone A. Prevention of cardiovascular disease: screening for magnesium deficiency. Cardiol Res Pract. 2019;2019:10. doi:10.1155/2019/4874921

22. Figueiredo MP, Cunha VRR, Leroux F, et al. Iron-based layered double hydroxide implants: potential drug delivery carriers with tissue biointegration promotion and blood microcirculation preservation. $A C S$ Omega. 2018;3(12):18263-18274. doi:10.1021/acsomega.8b02532
23. Mansouri E, Tarhriz V, Yousefi V, Dilmaghani A. Intercalation and release of an anti-inflammatory drug into designed three-dimensionally layered double hydroxide nanostructure via calcination-reconstruction route. Adsorption. 2020;26(6):835-842. doi:10.1007/ s10450-020-00217-4

24. Rabiee N, Bagherzadeh M, Ghadiri AM, Salehi G, Fatahi Y, Dinarvand R. ZnAl nano layered double hydroxides for dual functional CRISPR/Cas9 delivery and enhanced green fluorescence protein biosensor. Sci Rep. 2020;10(1):20672. doi:10.1038/s41598-02077809-1

25. Yousefi V, Tarhriz V, Eyvazi S, Dilmaghani A. Synthesis and application of magnetic@layered double hydroxide as an anti-inflammatory drugs nanocarrier. J Nanobiotechnology. 2020;18(1):155. doi:10.1186/s12951-020-00718-y

26. Saifullah B, Arulselvan P, El Zowalaty ME, et al. Development of a highly biocompatible antituberculosis nanodelivery formulation based on para-aminosalicylic acid - zinc layered hydroxide nanocomposites. Sci World J. 2014;2014:401460. doi:10.1155/2014/401460

27. Saifullah B, Hussein MZ, Hussein-Al-Ali SH, Arulselvan P, Fakurazi $\mathrm{S}$. Antituberculosis nanodelivery system with controlled-release properties based on para-amino salicylate-zinc aluminum-layered double-hydroxide nanocomposites. Drug Des Devel Ther. 2013;7:1365-1375.

28. Tucker KL, Hannan MT, Chen H, Cupples LA, Wilson PWF, Kiel DP. Potassium, magnesium, and fruit and vegetable intakes are associated with greater bone mineral density in elderly men and women. Am J Clin Nutr. 1999;69(4):727-736. doi:10.1093/ajcn/69.4.727

29. Cavani F, Trifirò F, Vaccari A. Hydrotalcite-type anionic clays: preparation, properties and applications. Catal Today. 1991;11(2):173301. doi:10.1016/0920-5861(91)80068-K

30. Rives V. Layered Double Hydroxides: Present and Future. Nova Science Pub Inc; 2001.

31. Salak ANV, Lukienko DEL, Shapovalov IM, et al. High-power ultrasonic synthesis and magnetic-field-assisted arrangement of nanosized crystallites of cobalt-containing layered double hydroxides. ChemEngineering MDPI. 2019;3(3):62.

32. Saifullah B, Hussein MZ. Inorganic nanolayers: structure, preparation, and biomedical applications. Int $J$ Nanomedicine. 2015;10:5609-5633.

33. Labille JGA, Bonasera A, Prestopino G. Layered double hydroxides: a toolbox for chemistry and biology. Crystals. 2019;9(7):361. doi:10.3390/cryst9070361

34. Cao Z, Li B, Sun L, Li L, Xu ZP, Gu Z. Targeted drug delivery: 2D layered double hydroxide nanoparticles: recent progress toward preclinical/clinical nanomedicine (small methods 2/2020). Small Methods. 2020;4(2):2070008. doi:10.1002/smtd.202070008

35. Boman G. Serum concentration and half-life of rifampicin after simultaneous oral administration of aminosalicylic acid or isoniazid. Eur J Clin Pharmacol. 1974;7(3):217-225. doi:10.1007/BF00560384

36. Traini D, Young PM. Drug delivery for tuberculosis: is inhaled therapy the key to success? Ther Deliv. 2017;8(10):819-821. doi:10.4155/tde-2017-0050

37. Goyal AK, Garg T, Bhandari S, Rath G. Chapter 22 - advancement in pulmonary drug delivery systems for treatment of tuberculosis. In: Andronescu E, Grumezescu AM, editors. Nanostructures for Drug Delivery. Elsevier; 2017:669-695.

38. Sharma R, Kaur A, Sharma AK, Dilbaghi N. Nano-based anti-tubercular drug delivery and therapeutic interventions in tuberculosis. Curr Drug Targets. 2017;18(1):72-86. doi:10.2174/ 1389450116666150804110238

39. El Zowalaty ME, Al Ali SHH, Husseiny MI, Geilich BM, Webster TJ, Hussein MZ. The ability of streptomycin-loaded chitosan-coated magnetic nanocomposites to possess antimicrobial and antituberculosis activities. Int J Nanomedicine. 2015;10:3269. doi:10.2147/IJN. S74469 
40. Hakkimane SS, Shenoy VP, Gaonkar SL, Bairy I, Guru BRJ Antimycobacterial susceptibility evaluation of rifampicin and isoniazid benz-hydrazone in biodegradable polymeric nanoparticles against Mycobacterium tuberculosis $\mathrm{H} 37 \mathrm{Rv}$ strain. Int $J$ Nanomedicine. 2018;13:4303. doi:10.2147/IJN.S163925

41. Walters SB, Hanna BA. Testing of susceptibility of Mycobacterium tuberculosis to isoniazid and rifampin by mycobacterium growth indicator tube method. J Clin Microbiol. 1996;34(6):1565-1567. doi:10.1128/jcm.34.6.1565-1567.1996

42. Tsiaggali M, Andreadou E, Hatzidimitriou A, Pantazaki A, Aslanidis PJ. Copper (I) halide complexes of N-methylbenzothiazole-2-thione: synthesis, structure, luminescence, antibacterial activity and interaction with DNA. J Inorg Biochem. 2013;121:121-128. doi:10.1016/j. jinorgbio.2013.01.001

43. Usman MS, El Zowalaty ME, Shameli K, Zainuddin N, Salama M, Ibrahim NAJ. Synthesis, characterization, and antimicrobial properties of copper nanoparticles. Int J Nanomedicine. 2013;8:4467.

44. Williams DN, Ehrman SH, Holoman TRPJ. Evaluation of the microbial growth response to inorganic nanoparticles. $J$ Nanobiotechnology. 2006;4(1):3. doi:10.1186/1477-3155-4-3

45. Phumpatrakom P, Ariyakriangkai W, Srisuwan T, Louwakul P. In vitro cytotoxicity of some hemostatic agents used in apicoectomy to human periodontal ligament and bone cells. Saudi Endod J. 2020;10 (1):21-27.

46. Sasaki T, Tamaki J, Nishizawa K, et al. Evaluation of cell viability and metabolic activity of a 3D cultured human epidermal model using a dynamic autoradiographic technique with a PET radiopharmaceutical. Sci Rep. 2019;9(1):10685. doi:10.1038/s41598-01947153-0

47. He W, Frost MC. Direct measurement of actual levels of nitric oxide (NO) in cell culture conditions using soluble NO donors. Redox Biol. 2016;9:1-14. doi:10.1016/j.redox.2016.05.002

48. Wang X, Pang H, Chen W, Lin Y, Ning G. Controllable fabrication of high purity $\mathrm{Mg}(\mathrm{OH}) 2$ nanoneedles via direct transformation of natural brucite. Mater Lett. 2014;120:69-72. doi:10.1016/j. matlet.2014.01.034

49. Maa X, Maa H, Jianga X, Jianga Z. Preparation of magnesium hydroxide nanoflowers from boron mud via anti-drop precipitation method. Mater Res Bull. 2014;56:6.

50. Saifullah B, Hussein MZ, Hussein-Al-Ali SH, Arulselvan P, Fakurazi $\mathrm{S}$. Sustained release formulation of an anti-tuberculosis drug based on para-amino salicylic acid-zinc layered hydroxide nanocomposite. Chem Cent J. 2013;7(1):72. doi:10.1186/1752-153X-7-72

51. Akkaya Y, Infrared AS. Raman spectra, ab initio calculations vibrational assignment of 4-aminosalicylic acid. Vib Spectrosc. 2006;42 (22):10. doi:10.1016/j.vibspec.2006.05.011

52. Panicker CY, John VH. FT-IR, FT-Raman and FT-SERS spectra of 4aminosalicylic acid sodium salt dihydrate. Spectrochim Acta A Mol Biomol Spectrosc. 2001;58(2):7.

53. Rabha A, Singh A, Grover S, Kumari A, Pandey B, Grover A. Structural basis for isoniazid resistance in KatG double mutants of Mycobacterium tuberculosis. Microb Pathog. 2019;129:152-160. doi:10.1016/j.micpath.2019.02.003

54. Heraldy E, Triyono T, Wijaya K, Santosa SJ. Mg/Al hydrotalcite-like synthesized from brine water for eosin yellow removal. Indo J Chem. 2011;11(2):6.
55. Wu L, Yu L, Xiao X, et al. Recent advances in self-supported layered double hydroxides for oxygen evolution reaction. Research. 2020;2020:17. doi:10.34133/2020/3976278

56. Gunasekaran S, Sailatha E, Seshadri S, Kumaresan S. FTIR and FT Raman spectra and molecular structural conformation of isoniazid. Indian J Pure Appl Phys. 2009;47:7.

57. Hong L, Zheng JW. HPLC analysis of para-aminosalicylic acid and its metabolite in plasma, cerebrospinal fluid and brain tissues.. $J$ Pharm Biomed Anal. 2011;54(5):9. doi:10.1016/j.jpba.2010.11.031

58. Saifullah B, El Zowalaty ME, Arulselvan P, et al. Synthesis, characterization, and efficacy of antituberculosis isoniazid zinc aluminum-layered double hydroxide based nanocomposites. Int $J$ Nanomedicine. 2016;11:3225-3237. doi:10.2147/IJN.S102406

59. Malaguarnera L. Influence of resveratrol on the immune response. Nutrients. 2019;11(5):946. doi:10.3390/nu11050946

60. Schwager J, Richard N, Widmer F, Raederstorff D. Resveratrol distinctively modulates the inflammatory profiles of immune and endothelial cells. BMC Complement Altern Med. 2017;17(1):171823. doi:10.1186/s12906-017-1823-z

61. van Loo G, Sze M, Bougarne N, et al. Antiinflammatory properties of a plant-derived nonsteroidal, dissociated glucocorticoid receptor modulator in experimental autoimmune encephalomyelitis. J Mol Endocrinol. 2010;24(2):310-322. doi:10.1210/ me.2009-0236

62. Soonthornsit N, Pitaksutheepong C, Hemstapat W, Utaisincharoen P, Pitaksuteepong T. In vitro anti-inflammatory activity of Morus alba 1. stem extract in LPS-stimulated RAW 264.7 cells. Evid Based Complement Alternat Med. 2017;2017:8. doi:10.1155/2017/3928956

63. Chen L, Deng H, Cui H, et al. Inflammatory responses and inflammation-associated diseases in organs. Oncotarget. 2017;9(6):72047218. doi:10.18632/oncotarget.23208

64. Gonçalves JM, Martins PR, Angnes L, Araki K. Recent advances in ternary layered double hydroxide electrocatalysts for the oxygen evolution reaction. New J Chem. 2020;44(24):9981-9997. doi:10.1039/D0NJ00021C

65. Saifullah B, Chrzastek A, Maitra A, et al. Novel anti-tuberculosis nanodelivery formulation of ethambutol with graphene oxide. Molecules. 2017;22(10):1560. doi:10.3390/molecules22101560

66. Choi G, Rejinold NS, Piao H, Choy J-H. Inorganic-inorganic nanohybrids for drug delivery, imaging and photo-therapy: recent developments and future scope. Chem Sci. 2021;12(14):5044-5063. doi:10.1039/D0SC06724E

67. Wu Y, Pang H, Liu Y, et al. Environmental remediation of heavy metal ions by novel-nanomaterials: a review. Environ Pollut. 2019;246:608-620. doi:10.1016/j.envpol.2018.12.076

68. Nabipour H, Jafari SH, Naderikalali E, Mozafari M. Mefenamic acidlayered zinc hydroxide nanohybrids: a new platform to elaborate drug delivery systems. J Inorg Organomet Polym Mater. 2018. doi:10.1007/s10904-018-0998-1

69. Hashim N, Sharif SNM, Muda Z, et al. Preparation of zinc layered hydroxide-ferulate and coated zinc layered hydroxide-ferulate nanocomposites for controlled release of ferulic acid. Mater Res Innov. 2019;23(4):233-245. doi:10.1080/14328917.2018.1444696 


\section{Publish your work in this journal}

The International Journal of Nanomedicine is an international, peerreviewed journal focusing on the application of nanotechnology in diagnostics, therapeutics, and drug delivery systems throughout the biomedical field. This journal is indexed on PubMed Central, MedLine, CAS, SciSearch ${ }^{\mathbb{B}}$, Current Contents ${ }^{\mathbb{B}} /$ Clinical Medicine,

Journal Citation Reports/Science Edition, EMBase, Scopus and the Elsevier Bibliographic databases. The manuscript management system is completely online and includes a very quick and fair peer-review system, which is all easy to use. Visit http://www.dovepress.com/ testimonials.php to read real quotes from published authors. 